\title{
Changing aetiological factors of hepatocellular carcinoma and their potential impact on the effectiveness of surveillance
}

\author{
Tommaso Stroffolini ${ }^{a}$, Franco Trevisani ${ }^{b}$, Giovanbattista Pinzello $^{c}$, Franco Brunello $^{d}$, \\ Maurizio A. Tommasini e, Massimo Iavarone ${ }^{\mathrm{f}}$, Vito Di Marco ${ }^{\mathrm{g}}$, Fabio Farinati ${ }^{\mathrm{h}}$, Paolo Del Poggio ${ }^{\mathrm{i}}$, \\ Franco Borzio $^{j}$, Mauro Borzio ${ }^{k}$, Eugenio Caturelli ${ }^{1}$, Maria Anna Di Nolfo ${ }^{m}$, Marta Frigerio ${ }^{\mathrm{b}, 1}$, \\ Giuseppina Brancaccio $^{\mathrm{n}, 1}$, Giovanni Battista Gaeta ${ }^{\mathrm{n}, *}$ \\ a Dipartimento Malattie Infettive e Tropicali, Policlinico Umberto I, Rome, Italy \\ b Dipartimento Medicina Clinica, Alma Mater Studiorum-Università di Bologna, Italy \\ c S.C. Epatologia e Gastroenterologia, A.O. Niguarda Cà Granda, Milan, Italy \\ d Divisione Gastro-Epatologia, Ospedale S. Giovanni Battista, Torin, Italy \\ e U.O. Medicina Generale-Epatologia, Istituto clinico Humanitas IRCCS, Rozzano, Italy \\ f I Divisione Gastroenterologia, IRCCS, Ospedale Maggiore, Università di Milano, Italy \\ ${ }^{g}$ Dipartimento Gastroenterologia, Università Palermo, Italy \\ h Dipartimento Gastroenterologia, Università di Padova, Italy \\ ${ }^{i}$ Divisione Medicina, Ospedale Treviglio, Italy \\ j U.O. Medicina Interna ed Epatologia, A.O. Fatebenefratelli, Milan, Italy \\ ${ }^{k}$ U.O.C. Gastroenterologia-Ospedale Melegnano, Italy \\ ${ }^{1}$ U.O. Gastroenterologia Ospedale Belcolle, Viterbo, Italy \\ m Divisione Medicina, Ospedale Bolognini, Seriate, Italy \\ n Dipartimento Medicina Interna e Specialistica, Unità Epatiti Virali Acute e Croniche, Seconda Università di Napoli, Italy
}

\section{A R T I C L E I N F O}

\section{Article history:}

Received 15 October 2010

Accepted 3 May 2011

\section{Keywords:}

Cancer stage

Epidemiology

Hepatitis

Hepatocellular carcinoma

Surveillance

\begin{abstract}
A B S T R A C T
Background: The aetiological factors of hepatocellular carcinoma may vary over time.

Aims: The study assessed the potential impact of the aetiological factors on the effectiveness of surveillance in real-world patients.

Methods: Multicentre, cross-sectional study enrolling consecutive hepatocellular carcinoma cases during a six month period.

Results: 1733 cases (1311 prevalent and 422 incident) were recruited (mean age 68.6 years; $46.1 \%$ cases over 70 years; $73.9 \%$ males; $95.3 \%$ with cirrhosis); $63.0 \%$ were hepatitis $C$ virus positive and $23.7 \%$ were virus negative. Amongst incident HCCs, $34.5 \%$ were single $\leq 3 \mathrm{~cm}$ and $54.4 \%$ met the Milan criteria; $61.6 \%$ were diagnosed during surveillance; virus negative patients showed the lowest rate of surveillance (51.0\%). Surveillance was an independent predictor of detecting single $\mathrm{HCCs} \leq 2 \mathrm{~cm}(\mathrm{O} . \mathrm{R} .=5.4$; $95 \%$ C.I. $=2.4-12.4$ ) or HCCs meeting the Milan criteria (O.R. =3.1; 95\% C.I. $=1.9-5.2)$. Compared with an earlier Italian survey, there was a higher proportion of elderly subjects $(P<0.01)$, Child-Pugh class $A$ cases $(P<0.01)$, of virus-negative patients $(P<0.01)$ and with single tumours $\leq 3 \mathrm{~cm}(P<0.01)$ and a lower prevalence of hepatitis $C$ virus positive individuals $(P<0.01)$.

Conclusion: HCC is characterised by a growing prevalence of elderly patients and cases unrelated to hepatitis virus infections. The application of surveillance must be implemented, particularly amongst non-viral patients.
\end{abstract}

(C) 2011 Editrice Gastroenterologica Italiana S.r.l. Published by Elsevier Ltd. All rights reserved.

\section{Introduction}

Ultrasonographic(US) surveillance of patients at risk of developing HCC is recommended to diagnose this cancer at an early stage,

\footnotetext{
* Corresponding author at: Dept. Internal and Specialistic Medicine - Seconda Università di Napoli, Via S. Pansini 5, 80131 Naples, Italy.

E-mail address: giovannib.gaeta@unina2.it (G.B. Gaeta).

1 Database assembly and management.
}

amenable to curative approaches [1,2]. The efficacy of US surveillance in detecting small nodules and improving survival has been demonstrated in HBsAg carriers with hepatitis by a randomised controlled study [3] and in cirrhotic patients by several prospective or retrospective cohort studies, mostly performed in single centres $[1,2]$. Therefore, US surveillance programmes of patients at risk are widely utilised in clinical practice.

The aetiology of chronic liver disease could influence the gross pathology of HCCs diagnosed during surveillance [4,5]. This could add clinical importance to the changing pattern of aetiological 


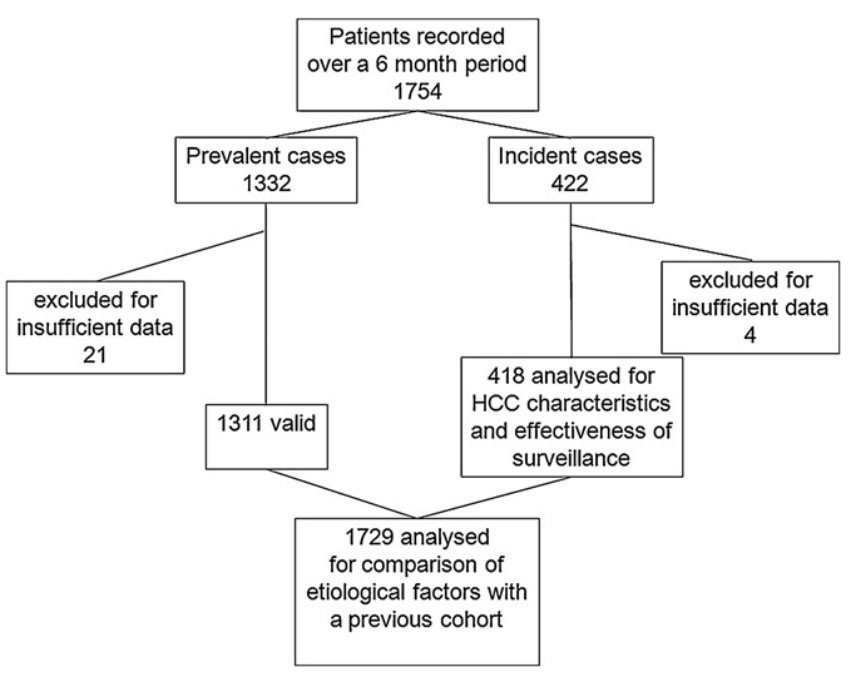

Fig. 1. Flow-chart of the study.

factors observed in several countries, including Italy where a multicentre study performed in 1996 showed that most (76.4\%) of HCC cases were positive for anti-hepatitis $\mathrm{C}$ virus (anti-HCV) antibody, whilst $12 \%$ had no markers of viral infection [6].

Our working hypothesis was that both the causes and the clinical presentation of HCC had been changing over the last decade, due to the epidemiologic variations of the risk factors and the growing diffusion of surveillance programmes (and the continuous improvement in the resolution of imaging techniques) in everyday practice. We therefore performed a nationwide survey involving specialised centres of various levels to assess the aetiological factors of HCC, the characteristics of the disease at diagnosis, the proportion of diagnoses made in patients under regular surveillance and the effectiveness of this practice in detecting early HCC across the various aetiological factors.

\section{Patients and methods}

The study recruited prospectively all HCC cases consecutively observed over a six-month period (October 2008-March 2009) in 23 hospitals throughout the country. We defined as incident cases all new HCCs diagnosed during the enrolment period and as prevalent cases those observed during the study period but detected previously. The data concerning each case were collected only once, at the first contact with the patient during the study period. All the areas of our country were adequately represented due to the large geographical distribution of the participating centres. Most of the centres had also participated in the above cited previous Italian investigation [6], which we used for the comparisons with the present study.

To minimise inter-centre variability in data generation, we established standard diagnostic protocols and procedures as a prerequisite to participating in the study. Liver cirrhosis was diagnosed by liver biopsy or in the presence of unequivocal clinical, biochemical and ultrasound signs [7]. The Child-Pugh criteria were used for the grading of cirrhosis [8]. The diagnostic criteria for HCC were: (1) histological, based on internationally accepted criteria [9] and (2) clinical, based on an alpha-fetoprotein (AFP) value greater than $200 \mathrm{ng} / \mathrm{ml}$ and evidence of focal liver lesions at imaging techniques, according to the guidelines of the European Association for the Study of the Liver (EASL) [1] or, for tumours diagnosed after 2005, of the American Association for the Study of the Liver (AASLD) [2]. Gross pathology of HCC was categorised according to Ohto et al. [10] as follows: nodular, multinodular and diffuse (mass not clearly defined, with indistinct boundaries). The cancer burden was assessed with abdominal US and abdominal computerised tomography $(\mathrm{CT})$ or magnetic resonance imaging (MRI), and chest X-ray in all patients. Additional investigations were performed only when clinically indicated. For each patient a pre-coded questionnaire compiled information regarding age, sex, hepatitis virus markers, amount of alcohol intake, the presence of cirrhosis, Child-Pugh score and the presence of oesophageal/gastric varices. For prevalent cases, information regarding the type and year of previous treatments was also recorded. The AFP value and gross pathologic types of HCC were recorded only in incident cases. The efficacy of surveillance was defined on the basis of an HCC diagnosis at the best stage for curative treatment ("very early stage": single nodule $\leq 2 \mathrm{~cm}$ ) or at a stage when curative options are still applicable, i.e., within the Milan criteria ("non-advanced stage": single nodule $\leq 5 \mathrm{~cm}$ or no more than 3 nodules, each $\leq 3 \mathrm{~cm}$, without vascular invasion and metastases) [11].

Informed consent was obtained from all patients and the study protocol was approved by the hospitals' ethical committees in conformity with the 1975 Declaration of Helsinki.

\subsection{Laboratory tests}

Markers of the hepatitis viruses and AFP were determined using the same commercial kits in all participating centres. Hepatitis markers were tested by enzyme immunoassay (EIA). Serum AFP was measured by ELISA, and an AFP value greater than $20 \mathrm{ng} / \mathrm{ml}$ was considered abnormal.

\subsection{Statistical analysis}

Differences between means and proportions were evaluated by Student's $t$-test and by a chi-squared test, respectively. A $P$ value $<0.05$ was considered statistically significant. In incident cases, independent predictors of detecting HCC at the best stage for curative treatment ("very early stage": single nodule $\leq 2 \mathrm{~cm}$ ) or at a stage when curative options are still applicable, i.e., within the Milan criteria ("non-advanced stage") were evaluated by multiple logistic regression analysis [12].

\section{Results}

The flow chart of the study is reported in Fig. 1. A total of 1739 HCC cases were analysed, of whom 1311 (75.7\%) were prevalent and 418 (24.3\%) incident cases. The mean age of all patients was 68.6 years, with nearly half of them (46.1\%) over 70 years of age. Only $5 \%$ were $\leq 50$ years old. Underlying cirrhosis was present in 95.3\% of cases, and $71.4 \%$ of these cases were in Child-Pugh class A. Oesophageal/gastric varices were detected in $52.5 \%$ of cases.

Amongst the 1587 cases tested for hepatitis virus markers, $60.3 \%$ were anti-HCV positive and HBsAg negative (amongst whom 778 cases were tested for anti-HBc with $34.4 \%$ found positive), $13.3 \%$ were $\mathrm{HBsAg}$ positive and anti-HCV negative, $2.7 \%$ were positive for both markers and as many as $23.7 \%$ were negative for both viral markers. Amongst the subjects who were negative for both hepatitis markers, $91.9 \%$ reported an alcohol intake $>4$ drinks daily ( $>40$ g/day) and 22.6\% (309 tested) were anti-HBc positive.

Amongst prevalent cases, $26.5 \%$ had HCC detected at least 4 years before and $92.8 \%$ reported a previous treatment. Prevalent cases were older than incident cases (68.9 years vs. 67.5 years; $P<0.0001$ ); this reflects the time lapse between the diagnosis and the current observation. Age distribution of the 422 incident cases showed that $39.7 \%$ of males and $60.8 \%$ of females, respectively, were $>70$ years of age. The incident cases showed a higher proportion of subjects negative for both hepatitis virus markers (27.8\% vs. $22.4 \%$; $P=0.025$ ) and a lower proportion of anti-HCV positive subjects, 
Table 1

Characteristics of hepatocellular carcinoma cases, according to recruitment pattern.

\begin{tabular}{|c|c|c|c|c|}
\hline Characteristic & Prevalent $N 1311$ & Incident $N 418$ & All & $P$ value \\
\hline Mean age (years) & $68.9 \pm 9.1$ & $67.5 \pm 10.6$ & $68.6 \pm 9.5$ & $<0.0001$ \\
\hline Male sex & $73.9 \%$ & $74.1 \%$ & 73.9 & NS \\
\hline Presence of cirrhosis & $95.5 \%$ & $94.7 \%$ & $95.3 \%$ & NS \\
\hline \multicolumn{5}{|c|}{ Child-Pugh class } \\
\hline A & $71.6 \%$ & $70.8 \%$ & $71.4 \%$ & \\
\hline $\mathrm{B}$ & $22.3 \%$ & $20.6 \%$ & $21.9 \%$ & NS \\
\hline C & $6.1 \%$ & $8.6 \%$ & $6.7 \%$ & \\
\hline Oesophageal varices & $53.0 \%$ & $50.8 \%$ & $52.5 \%$ & NS \\
\hline \multicolumn{5}{|c|}{ Hepatitis virus markers ${ }^{\mathrm{a}}$} \\
\hline${ }^{\mathrm{b}} \mathrm{HBsAg}-/ \mathrm{HCV}-$ & $22.4 \%$ & $27.8 \%$ & $23.7 \%$ & 0.025 \\
\hline $\mathrm{HBsAg}-/ \mathrm{HCV}+$ & $61.6 \%$ & $56.1 \%$ & $60.3 \%$ & 0.039 \\
\hline $\mathrm{HBsAg}+/ \mathrm{HCV}-$ & $13.0 \%$ & $14.3 \%$ & $13.3 \%$ & N.S \\
\hline $\mathrm{HBsAg}+/ \mathrm{HCV}+$ & $3.0 \%$ & $1.8 \%$ & $2.7 \%$ & N.S \\
\hline Previous treatment & $92.8 \%$ & na & & \\
\hline \multicolumn{5}{|c|}{ Years from HCC diagnosis } \\
\hline$\leq 1$ & $22.2 \%$ & na & & \\
\hline 2 & $38.4 \%$ & na & & \\
\hline 3 & $12.9 \%$ & na & & \\
\hline$\geq 4$ & $26.5 \%$ & na & & \\
\hline
\end{tabular}

na = not applicable. HBsAg, Hepatitis B surface antigen; HCV, hepatitis C virus; HCC, hepatocellular carcinoma.

a Global $P$ value $=0.11$.

b $91.1 \%$ reported $>4$ alcoholic drinks/day and $22.6 \%$ were anti-HBc positive.

with or without HBsAg (57.9\% vs. $64.6 \%, P=0.013$ ). The sex ratio, prevalence of cirrhosis, Child-Pugh class distribution and the proportion of HBsAg carriers (with or without HCV coinfection) were similar (Table 1 ).

Presenting features of incident HCCs are reported in Table 2. Diagnosis was made during US surveillance in $61.6 \%$ of them. The AFP values were normal ( $<20 \mathrm{ng}$ ) in $50.8 \%$ of cases. A single nodule was detected in $59.1 \%$ of cases; $34.8 \%$ of solitary HCC were $\leq 2 \mathrm{~cm}$ and $60.5 \%$ were $\leq 3 \mathrm{~cm}$. Interestingly, $192(54.5 \%)$ incident tumours met the Milan criteria but only $39 \%$ of them were $\leq 65$ years old.

The anti-HCV positive/HBsAg negative patients were older (69.1 years), had the lowest sex ratio (M/F 1.7:1) and showed the highest proportion of subjects under regular US surveillance (68.8\%) (Table 3). In contrast, patients who were anti-HCV negative/HBsAg negative showed the lowest proportion of subjects under regular

Table 2

Tumour characteristics at diagnosis in incident cases of hepatocellular carcinoma (HCC).

\begin{tabular}{lc}
\hline U.S. Surveillance (no. 401) & \\
No & $154(38.4 \%)$ \\
Yes & $247(61.6 \%)$ \\
Alpha-fetoprotein (no. 392) & \\
$\quad \leq 20$ ng & $199(50.8 \%)$ \\
$21-200$ ng & $118(30.1 \%)$ \\
$>200$ ng & $75(19.1 \%)$ \\
HCC gross pathology (no. 418) & \\
$\quad$ Solitary & $247(59.1 \%)$ \\
Multinodular & $135(32.3 \%)$ \\
Diffuse & $36(8.6 \%)$ \\
Diameter of solitary HCC (cm) (no. 242) \\
$\quad \leq 2$ & \\
$2.1-3$ & $84(34.8 \%)$ \\
$3.1-5$ & $62(25.7 \%)$ \\
$>5$ & $63(26.1 \%)$ \\
Number of lesions (multinodular HCC) (no. 132) & $33(13.4 \%)$ \\
$\leq 2$ & \\
3 & $70(53.0 \%)$ \\
$>3$ & $26(19.7 \%)$ \\
Diameter of the biggest nodule (multinodular HCC) (cm; no. 63) & $36(27.3 \%)$ \\
$\leq 2$ & $15(23.8 \%)$ \\
$2.1-3$ & $18(28.6 \%)$ \\
$3.1-5$ & $15(23.8 \%)$ \\
$>5$ & $15(23.8 \%)$ \\
Macroscopic vascular invasion (no. 402) & $60(14.9 \%)$ \\
Metastases (no. 167) & $6(3.6 \%)$ \\
\hline
\end{tabular}

surveillance. HCV positive patients more frequently (62.1\%) presented with a single nodule, whilst HBsAg positive cases more frequently $(12.7 \%)$ showed an infiltrative tumour. However, these tendencies did not reach statistical significance.

Surveillance had been performed twice a year in $80.3 \%$ of cases and annually in $19.7 \%$. There were no significant differences in the presenting features of HCC according to the interval of surveillance (data not shown).

Subjects under US surveillance had a lower male preponderance $(P<0.0001)$ and more frequently had cirrhosis $(97.5 \%$ vs. $90.1 \%$; $P=0.003$ ) (Table 4). The AFP values were in the normal range at the time of HCC diagnosis in $55.4 \%$ of the patients under surveillance, whereas this figure decreased to $43.8 \%$ in patients not under surveillance. Only $13.9 \%$ of patients under surveillance had AFP values $>200 \mathrm{ng} / \mathrm{ml}$ at the time of HCC diagnosis whilst this figure increased to $27.7 \%(P=0.001)$ in not surveyed cases. Diagnosis during surveillance was associated with a higher proportion of solitary nodules ( $65.6 \%$ vs. $47.1 \% ; P<0.0001)$, the mean diameter of which was lower $(3.0 \mathrm{~cm}$ vs. $4.3 \mathrm{~cm} ; P<0.0001)$ compared to the counterpart. In the case of multinodular HCC, the mean number of nodules was lower ( 2.6 vs. $4.1 ; P<0.0001)$, with a lower mean diameter of the biggest lesion $(2.9 \mathrm{~cm}$ vs. $5.1 \mathrm{~cm} ; P<0.0001)$. Lastly, the macroscopic vascular invasion was less frequent ( $9.2 \%$ vs. $26.4 \%$; $P<0.0001)$. The favourable impact of surveillance on the prevalence of metastasis did not reach statistical significance, due to the low rate of extra-hepatic tumour spread.

Two models were run to identify independent predictors of the likelihood of detecting HCCs at a stage amenable to curative treatments (Table 5). In the first model the outcome variable was a "very early stage" ( single nodule $\leq 2 \mathrm{~cm}$ ), whilst in the second model it was a "non-advanced stage" according to the Milan criteria [17]. A preliminary analysis showed no association between these two outcomes and the centre size. After adjustment for the confounding factors (age, gender, surveillance, aetiologies, AFP levels, cirrhosis), US surveillance was strongly associated with the likelihood of detecting both a very early tumour $($ O.R. $=5.4 ; 95 \%$ C.I. $=2.4-12.4)$ and a non-advanced HCC (O.R. $=3.1 ; 95 \%$ C.I. $=1.9-5.2)$.

Finally, in order to have an insight into the changes in aetiological factors over time, we compared the whole present series to the 1148 Italian patients collected eleven years earlier [6,13]. This comparison showed that in the present study: (1) HCC patients were older (68.6 years vs. 64.5 years; $P<0.0001$ ); (2) the proportion of cirrhotic cases in Child-Pugh A class was higher (71.4\% vs. $55.6 \%$; $P<0.0001$ ); (3) the prevalence of anti-HCV positive subjects, with or without HBsAg positivity, was lower (63.0\% vs. 76.4\%; $P<0.0001)$, whilst that of subjects without virus markers doubled $(23.7 \%$ vs. $12.1 \% ; P<0.0001)$; this trend was recorded even when comparing patients below 50 years of age ( $25.6 \%$ vs. $12.8 \%$ ); (4) solitary HCCs $\leq 3 \mathrm{~cm}$ were more frequent ( $34.5 \%$ vs. $27.2 \%$; $P=0.01$ ); (5) the proportion of HCC cases without underlying cirrhosis dropped from 6.9 to $4.7 \%(P=0.019)$.

\section{Discussion}

This is a large series of HCC cases recruited in a short time period (6 months), which avoided the time-dependent "enrolment bias", that is, the variability of results due to the changes over time in the risk factors, mode of surveillance, advances in diagnostic techniques and treatment strategies, which can affect the validity of the results observed.

In our setting, HCC was mainly caused by HCV infection and developed in adult-old cirrhotic patients. These epidemiologic features are expected in a country where HCV contaminated many individuals over the first three decennia following the second world war, due to a widespread use of non disposable syringes and 
Table 3

Characteristics of hepatocellular carcinoma incident cases according to hepatitis virus markers. HBV-HCV coinfected patients (1.8\%) were excluded from the analysis.

\begin{tabular}{|c|c|c|c|c|}
\hline Characteristic & $\mathrm{HBsAg}-/ \mathrm{HCV}-($ no. 106) & HBsAg-/HCV+ (no. 214) & $\mathrm{HBsAg}+/ \mathrm{HCV}-($ no. 55) & $P$ value \\
\hline Mean age (years) & $67.5 \pm 9.8^{\mathrm{a}}$ & $69.1 \pm 10.6^{b}$ & $61.2 \pm 9.6^{c}$ & 0.003 \\
\hline Sex ratio $(M / F)$ & $14.1: 1^{\mathrm{d}}$ & $1.7: 1^{\mathrm{f}}$ & $5.7: 1^{g}$ & N.S \\
\hline Presence of cirrhosis & $92.2 \%$ & $97.2 \%$ & $96.3 \%$ & N.S \\
\hline \multicolumn{5}{|l|}{ Child-Pugh class } \\
\hline A & $67.4 \%$ & $68.4 \%$ & $81.5 \%$ & N.S \\
\hline$B+C$ & $32.6 \%$ & $31.6 \%$ & $18.5 \%$ & \\
\hline Presence of oesophageal varices & $52.2 \%$ & $52.2 \%$ & $45.4 \%$ & N.S \\
\hline \multicolumn{5}{|l|}{ Alpha-fetoprotein } \\
\hline$\leq 20 \mathrm{ng}$ & $58.0 \%$ & $47.5 \%$ & $49.9 \%$ & \\
\hline $21-200 \mathrm{ng}$ & $25.0 \%$ & $33.7 \%$ & $28.6 \%$ & \\
\hline$>200 \mathrm{ng}$ & $17.0 \%$ & $18.8 \%$ & $22.5 \%$ & N.S. \\
\hline Surveillance, yes & $51.0 \%{ }^{\mathrm{h}}$ & $68.8 \% \mathrm{~m}$ & $60.4 \%^{\mathrm{n}}$ & 0.03 \\
\hline \multicolumn{5}{|l|}{ Gross pathologic type } \\
\hline Single & $55.7 \%$ & $62.1 \%$ & $54.6 \%$ & \\
\hline Multinodular & $34.0 \%$ & $33.2 \%$ & $32.7 \%$ & \\
\hline Diffuse & $10.4 \%$ & $4.7 \%$ & $12.7 \%$ & N.S \\
\hline
\end{tabular}

a vs. b: $P=$ NS; d vs. f: $P=0.0001$; h vs. $\mathrm{m}: P=0.0031$.

a vs. c: $P=<0.0001$; d vs. $\mathrm{g}: P=0.15$; h vs. $\mathrm{n}: P=\mathrm{NS}$.

b vs. c: $P=<0.0001 ; m$ vs. $\mathrm{n}: P=\mathrm{NS}$.

Table 4

Characteristics of hepatocellular carcinoma incident cases according to ultrasonographic surveillance.

\begin{tabular}{|c|c|c|c|}
\hline Characteristic & Surveillance $(N=257)$ & No Surveillance $(N=154)$ & $P$ value \\
\hline Mean age (years) & $68.0 \pm 9.7$ & $66.9 \pm 9.3$ & N.S. \\
\hline Sex ratio $(M / F)$ & $2.1: 1$ & $5.6: 1$ & $<0.0001$ \\
\hline Presence of cirrhosis & $97.5 \%$ & $90.1 \%$ & 0.003 \\
\hline \multicolumn{4}{|l|}{ Alpha-fetoprotein } \\
\hline$\leq 20 \mathrm{ng}$ & $55.4 \%$ & $43.8 \%$ & \multirow[t]{3}{*}{0.0019} \\
\hline $21-200$ ng & $30.7 \%$ & $28.5 \%$ & \\
\hline$>200 \mathrm{ng}$ & $13.9 \%$ & $27.7 \%$ & \\
\hline \multicolumn{4}{|l|}{ Hepatitis virus markers } \\
\hline HBsAg-/HCV- & $23.1 \%$ & $36.7 \%$ & \multirow{4}{*}{0.01} \\
\hline $\mathrm{HBsAg}-/ \mathrm{HCV}+$ & $61.6 \%$ & $46.0 \%$ & \\
\hline $\mathrm{HBsAg}+/ \mathrm{HCV}-$ & $14.0 \%$ & $15.1 \%$ & \\
\hline $\mathrm{HBsAg}+/ \mathrm{HCV}+$ & $1.3 \%$ & $2.2 \%$ & \\
\hline \multicolumn{4}{|l|}{ HCC gross pathology } \\
\hline Single & $65.6 \%$ & $47.1 \%$ & \multirow[t]{3}{*}{$<0.0001$} \\
\hline Multinodular & $30.8 \%$ & $35.3 \%$ & \\
\hline Diffuse & $3.6 \%$ & $17.6 \%$ & \\
\hline Mean diameter of single HCCs $(\mathrm{cm})$ & $3.0 \pm 2.2$ & $4.3 \pm 2.5$ & $<0.0001$ \\
\hline Mean diameter of the biggest nodule ( $\mathrm{cm}$ ) (multinodular HCC) & $2.9 \pm 1.4$ & $5.1 \pm 2.4$ & $<0.0001$ \\
\hline Mean number of nodules (multinodular HCC) & $2.6 \pm 1.3$ & $4.1 \pm 2.7$ & $<0.0001$ \\
\hline Macroscopic vascular invasion & $9.2 \%$ & $26.4 \%$ & $<0.0001$ \\
\hline Metastases & $2.2 \%$ & $5.6 \%$ & N.S. \\
\hline
\end{tabular}

HBsAg, Hepatitis B surface antigen; HCV, hepatitis C virus; HCC, hepatocellular carcinoma.

other medical devices [14]. However, the terminating phase of the "cohort" effect of this HCV epidemic spread on HCC epidemiology is testified by not only the downward trend in HCC mortality [15] but also by the shift towards older ages and the decreasing prevalence of HCV-related cases (from 76.4\% to 64.0\%) we observed with respect to a previous investigation. Our scenario is in sharp contrast with the trend observed in United States, where the proportion of HCV-related HCCs is increasing and will continue to increase [16] since the anti-HCV prevalence peaks in young adults, as a result of a relatively recent spread of HCV circulation in the US population, mainly caused by intravenous drug use and high-risk sexual behaviour [17].

Besides the decreasing impact of HCV, we found a doubling of HCCs negative for hepatitis virus markers (from $12.1 \%$ to $23.7 \%$ ), which was recorded even in younger patients. An alcohol abuse was the backbone for liver disease progression in most of these patients, since $91.9 \%$ reported a daily intake of $>4$ drinks; in some patients, HBV occult infection might have played a contributory role, as suggested by the presence of anti-HBc antibodies [18]. We could not evaluate the role of metabolic syndrome, an emerging major risk (co)factor for HCC in developing countries [19,20].

Combining the prevalent and incident cohorts in determining the changes in the aetiological factors over time might suffer from a potential "survival bias". However, whilst aetiological factors entail a different degree of risk for HCC development, they have no or minimal effect on the outcome of HCC cases [4], making negligible the impact of this bias as far as the reliability of our aetiologic data. Conversely, it cannot be excluded a certain role of the survival

Table 5

Factors associated with the likelihood of detecting hepatocellular carcinoma cases at a favourable stage for effective treatment. Adjusted odds ratios (O.R.) derived by multiple logistic regression analysis.

\begin{tabular}{|c|c|c|}
\hline Factor & $\begin{array}{l}\text { First model } \\
\text { Outcome variable = single } \\
\text { nodule } \leq 2 \mathrm{~cm} \\
\text { Adjusted O.R. }(95 \% \text { C.I.) }\end{array}$ & $\begin{array}{l}\text { Second model } \\
\text { Outcome variable = Milan } \\
\text { criteria }^{\mathrm{a}} \\
\text { Adjusted O.R. (95\% C.I.) }\end{array}$ \\
\hline \multicolumn{3}{|l|}{ Age } \\
\hline$>60$ years & 1 & 1 \\
\hline$\leq 60$ years & $2.0(1.0-4.1)$ & $1.3(0.7-2.4)$ \\
\hline \multicolumn{3}{|l|}{ Gender } \\
\hline Male & 1 & 1 \\
\hline Female & $1.4(0.7-2.9)$ & $1.2(0.7-2.2)$ \\
\hline \multicolumn{3}{|l|}{ Surveillance } \\
\hline No & 1 & 1 \\
\hline Yes & $5.4(2.4-12.4)$ & $3.1(1.9-5.2)$ \\
\hline
\end{tabular}

a Milan criteria: one nodule $\leq 5 \mathrm{~cm}$ or $\leq 3$ nodules each $\leq 3 \mathrm{~cm}$, without vascular and lymphonodal invasion. 
on variables such as Child-Pugh class and presence of oesophageal varices. Caution in interpreting the equivalence between prevalent and incident cases is needed since less compromised patients could have been favoured. However, the proportions of incident and prevalent cases were similar in the two cohorts of patients collected at a distance of eleven years.

An US-based surveillance of cirrhotic patients is recommended for the early detection of HCC $[1,2]$ as it can detect small asymptomatic tumours still amenable to curative or effective treatment. An encouraging feature was the higher proportion of patients diagnosed with a solitary small HCC and in Child-Pugh A class we found as compared with the previous survey. This stage migration phenomenon was likely due to the increasing proportion of cirrhotic patients who are maintained under regular US vigilance in clinical practice. In this respect, our "real world" survey confirms the efficacy of surveillance, since it was able to significantly increase the number of solitary small tumours and, hence, with a lesser likelihood of vascular invasion and recurrence after treatment. The multivariate analysis confirmed that US surveillance remarkably increases the likelihood of detecting HCC at a very early stage or a tumour still meeting the Milan criteria. However, due to the increasing age of the patients at diagnosis of HCC, it is conceivable that liver transplantation will be an option to reduce over time.

Our results add further strength to the guideline recommendation, as they were generated by the real world experience. Indeed, a notable feature of the study design is the participation of both referral and peripheral centres throughout the country. To minimise inter-centre variability in data generation, we established standard diagnostic protocols and procedures as a pre-requisite to participating in the study. This avoided that the provenience could act as an independent determinant of the cancer burden at the time of diagnosis, as demonstrated by the lack of difference in diagnosis burden amongst centres of different sizes. The use of US surveillance should be further extended because nearly $40 \%$ of new HCC cases are still diagnosed outside surveillance. This drawback was particularly evident in men and in patients without seromarkers of viral infection, amongst whom about $50 \%$ of HCCs were diagnosed outside surveillance. The relation between patient sex and prevalence of HCC detected by surveillance has been already reported [21] and can be tentatively attributed to a lower compliance to surveillance of men and, particularly, of alcohol abusers (who are more frequently males than females). However, other two factors may have contributed: first, compared to viral cases, the oncological risk in non viral patients is probably underestimated by physicians. Second, alcohol related liver cirrhosis usually has an insidious subclinical course, leading to the diagnosis only in decompensated or neoplastic stage. These points need great attention, due to the increasing proportion of non-viral liver disease.

The use of AFP alone for HCC surveillance is discouraged [2] and its use in addition to US is controversial [22]. In fact, an AFP $>200 \mathrm{ng} / \mathrm{ml}$ is highly specific for HCC diagnosis in cirrhosis patients with imaging evidence of HCC, but its sensitivity is very low as one third of HCC patients have AFP levels $>100 \mathrm{ng} / \mathrm{ml}$, and only $22 \%$ of cases reach a value $>00 \mathrm{ng} / \mathrm{ml}[22]$. Accordingly, as many as $55.4 \%$ of incident cases diagnosed during US surveillance had a normal AFP, and only $24.5 \%$ and $19.1 \%$ had an AFP value higher than $100 \mathrm{ng} / \mathrm{ml}$ and $200 \mathrm{ng} / \mathrm{ml}$, respectively. Our survey fully confirms the insensitivity of this oncomarker as surveillance test.

In conclusion, this study shows that both the epidemiological pattern and presenting features of HCC in Italy are changing. The most important changes concerning risk factors are the decreasing prevalence of HCV-related cases and a mounting proportion of tumours unrelated to virus infections. This information should stimulate studies aimed at the recognition of suitable biomarkers for non-viral liver disease and molecular signature of initiation and progression of HCC [23]. The efficacy of US surveillance as a tool for achieving an early diagnosis of HCC is confirmed in our real world setting, even in patients with non-viral liver disease. However, its efficiency should be improved, particularly amongst men and nonviral patients, in whom peculiar attention should be paid to avoid a suboptimal compliance to this practice and/or its underutilisation.

\section{Conflicts of interest}

None declared.

\section{Appendix A. Collaborating group}

Gianluca Cuomo (Malattie Infettive, Seconda Università di Napoli), Marco Zoli, Donatella Magalotti (Dipartimento di Medicina Interna, dell'Invecchiamento e Malattie Nefrologiche, Alma Mater Studiorum-Università di Bologna), Marta Frigerio (Dipartimento Medicina Clinica, Alma Mater Studiorum-Università di Bologna), Emanuela Medda (Istituto Superiore Sanità, Roma), Guido Colloredo, Miranda Sonzogni (U.O. Medicina, Policlinico S. Pietro, Bergamo), Edoardo Giovanni Giannini, Elena Marabotto (Gastroenterologia, Università di Genova), Giorgio Bellati, Alberto Colombo (Medicina Interna, Como), Luigi Roffi, Valentina Sellia (Medicina Interna, Sondrio) Giampietro Zabbialini (Dipartimento Chirurgia, Ospedale Treviglio), Andrea Capretti, Giovanni Fanelli (U.O.C. Gastroenterologia, Ospedale S. Carlo Borromeo, Milano), Guido Gubertini, Elena Angeli (Malattie Infettive Ospedale Sacco, Milano), Alessandro Metallinos (Gastroenterologia, Università L'Aquila), Maria Grazia Lea Pich (Medicina Interna, Humanitas, Milano), Paola Roselli (Gastroenterologia, Viterbo), Mariella Molaro (Divisione Medicina, Ospedale Seriate), Giuseppe Cabibbo (Gastroenterologia, Università Palermo), Riccardo Bottelli, Daniela Sala (U.O. Medicina, Ospedale Angera), Elena Gentilcore (Ospedale S. Giovanni Battista, Torino), Angelo Sangiovanni (Gastroenterologia, Milano), Claudia Pedicino (Gastroenterologia, Melegnano), Claudio Zavaglia (S.C. Epatologia e Gastroenterologia, A.O. Niguarda Cà Granda, Milano), Anna Giacomin (Dipartimento Gastroenterologia, Università di Padova).

\section{References}

[1] Bruix J, Sherman M, Llovet JM, et al. Clinical management of hepatocellular carcinoma. Conclusions of the Barcelona 2000 EASL conference. European Association for the study of the liver. J Hepatol 2001;35:421-30.

[2] Bruix J, Sherman M. Management of hepatocellular carcinoma. Hepatology 2005;42:1208-36

[3] Zhang BH, Yang BH, Tang ZY. Randomized controlled trial of screening for hepatocellular carcinoma. J Cancer Res Clin Oncol 2004;127:35-50.

[4] Trevisani F, Magini G, Santi V, et al. Impact of etiology of cirrhosis on the survival of patients diagnosed with hepatocellular carcinoma during surveillance. Am J Gastroenterol 2007;102:1022-31.

[5] Benvegnù L, Noventa F, Bernardiello E, et al. Evidence for an association between etiology of cirrhosis and pattern of hepatocellular carcinoma development. Gut 2001;48:110-5.

[6] Stroffolini T, Andreone P, Andriulli A, et al. Characteristics of hepatocellular carcinoma in Italy. J Hepatol 1998;29:942-4.

[7] Gaiani S, Gramantieri L, Venturoli N, et al. What is the criterion for differentiating chronic hepatitis from compensated cirrhosis? A prospective study comparing ultrasonography and percutaneous liver biopsy. J Hepatol 1997;27:979-98.

[8] Pugh RN, Murray-Lyon IM, Dawson JL, et al. Transection of the oesophagus for bleeding oesophageal varices. Br J Surg 1973;60:646-9.

[9] Kondo F, Ebara M, Sugiura N, et al. Histological features and clinical course of a large regenerative nodules: evaluation of their precancerous potentially. Hepatology 1990;12:592-8.

[10] Otho M, Ebara M, Okuda F. Ultrasonography in the diagnosis of hepatic tumor. In: Okuda F, Ishak KG, editors. Neoplasms of the liver. Tokyo: Springer; 1987. p. $252-8$.

[11] Mazzaferro V, Regalia E, Doci R, et al. Liver transplantation for the treatment of small hepatocellular carcinoma in patients with cirrhosis. $\mathrm{N}$ Engl J Med 1996;334:693-9.

[12] Kleinbaum DG, Kupper LL, Chambless LE. Logistic regression analysis of epidemiological data-theory and practice. Commun Stat Theor Methods 1982;71:485-547.

[13] Stroffolini T, Andreone P, Andriulli A, et al. Gross pathologic types of hepatocellular carcinoma in Italy. Oncology 1999;56:189-92. 
[14] Chiaramonte M, Stroffolini T, Lorenzoni U, et al. Risk factors in communityacquired hepatitis $C$ virus chronic infection: a case-control study in Italy. J Hepatol 1996;24:129-34.

[15] Bosetti C, Levi F, Boffetta P, et al. Trends in mortality from hepatocellular carcinoma in Europe. Hepatology 2008;48:137-45.

[16] Rein DB, Wittenborn JS, Weinbaum CM, et al. Forecasting the morbidity and mortality associated with prevalent cases of pre-cirrhotic chronic hepatitis $\mathrm{C}$ in the United States. Dig Liver Dis 2011;43:66-72.

[17] Alter MJ, Kruszon-Moran D, Naiman OV, et al. The prevalence of hepatitis C virus infection in the United States, 1988-94. N Engl J Med 1999;341:556-62.

[18] Raimondo G, Allain JP, Brunetto MR, et al. Statements from the Taormina expert meeting on occult hepatitis B virus infection. J Hepatol 2008;49:652-7.
[19] Calle EE, Rodriguez C, Walker-Thurmond K, et al. Overweight, obesity and mortality from cancer in a prospective studied cohort of US adults. N Engl J Med 2003;348:1625-38.

[20] Nair G, Mason A, Eason J, et al. Is obesity an independent risk factor for hepatocellular carcinoma in cirrhosis? Hepatology 2002;36:150-5.

[21] Farinati F, Sergio A, Giacomin A, et al. Is female gender a significant favorable prognostic factor in hepatocellular carcinoma? Eur J Gastroenterol Hepatol 2009:1212-8.

[22] Bolondi L. Screening for hepatocellular carcinoma in cirrhosis. J Hepatol 2003;39:1076-84.

[23] Villanueva A, Newell P, Chiang DY, et al. Genomics and signalling pathways in hepatocellular carcinoma. Semin Liver Dis 2007;27:55-76. 